\title{
An Update on Targeted Therapies in Renal Cell Carcinomas
}

\section{Ajaz $\mathrm{S}^{1 *}$ and $\mathrm{Abid} \mathrm{A}^{2}$}

${ }^{1}$ Dr. Panjwani Center for Molecular Medicine and Drug Research (PCMD), International Center for Chemical and Biological Sciences (ICCBS), University of Karachi, Karachi, Pakistan

${ }^{2}$ Centre for Human Genetics and Molecular Medicine, Sindh Institute of Urology and Transplantation (SIUT), Karachi, Pakistan

\begin{abstract}
The advancements in understanding of biological mechanisms in RCCs have led to the development and application of targeted therapies. The FDA approved targeted therapies are mainly directed against angiogenesis, mTOR pathways, and immune checkpoint inhibition. VEGF overexpression due to VHL gene mutation or alteration in majority of RCCs makes it one of the most suitable targets for development of therapy. Inhibitors and antibodies against VEGF or VEGFR have shown promising results in metastatic RCCs. mTOR pathway inhibition has also proven to be an efficacious strategy as well as antibodies targeting the immune checkpoints allowing T-Cells to attack tumour cells. However, there is need for improvement as certain proportion of patients may either not respond or develop resistance against targeted therapies.
\end{abstract}

Keywords: Angiogenesis inhibition; mTOR Pathway inhibition; Immune checkpoint inhibition; Mechanism of action; VEGF; VEGFR; mRCC

\section{Introduction}

Renal cell carcinomas (RCCs), arising from renal parenchyma, comprise $90 \%$ of the kidney cancers [1]. RCCs are chemotherapy and radiotherapy resistant. The mainstream treatment is surgery. Immunotherapy, including cytokines such as interferon- $\alpha$ (IFN- $\alpha$ ) and interleukin 2 (IL-2), has shown some efficacy. However, the treatment has toxic side-effects [2]. In the recent years, the increased knowledge of underlying biological mechanisms in RCCs has led to the development and application of targeted therapies.

Targeted therapies approved by the US Food and Drug Administration (FDA) in the treatment of advanced RCC are listed in Table 1 [3]. These are directed against angiogenesis, mTOR pathways or immune checkpoints.

\section{Angiogenesis inhibitors in RCCs}

The mechanism of angiogenesis is a key target for the metastatic RCC (mRCC). More than $80 \%$ of sporadic RCC cases are caused by the disruption of the VHL gene [4]. pVHL deficiency results in hypoxia inducible factor (HIF) accumulation. Transcription of down-stream genes promotes angiogenesis, cell growth and glycolysis through the activation of vascular endothelial growth factor (VEGF), transforming growth factor (TGF) $\alpha$ and $\beta$, and platelet derived growth factor (PDGF). Most of the therapies approved in RCCs target these proteins and their corresponding receptors [5]. Therapeutic strategies in kidney cancer include the blockade of VEGF by monoclonal antibodies and the inhibition of VEGF receptor (VEGFR) by tyrosine kinase inhibitors. These antiangiogenic therapies may also be given in combination with conventional chemotherapy. Treatment options that target VEGF and VEGFR improve the progression free survival of patients with advanced RCC significantly to more than 26 months in recent randomized trials [6].

\section{mTOR pathways inhibition in RCCs}

The mammalian target of rapamycin (mTOR) is an intracellular signalling pathway in which mTOR is a protein kinase involved in the regulation of cellular functions such as proliferation, growth and survival. Rapamycin is an allosteric inhibitor of mTOR. Everolimus, a rapamycin analog (rapalog) has been approved by FDA for renal cell carcinoma along with other specific cancers. Mostly, therapeutic effects lead to disease stabilization rather than tumor regression. Thus, combination treatments with chemotherapeutic or small molecule inhibitor agents are advised [7]. Temsirolimus is an anti-angiogenesis and mTOR inhibitor. By activation of mTOR, c-Myc, and HIF-1a will be stimulated, which results in an increase in genes that promote VEGF-associated angiogenesis, proliferation (cyclin D1), and cell survival (survivin). The inhibition leads to decease in concentration of down-stream targets [8].

\section{Immune checkpoint inhibition antibodies in RCCs}

Targeting inhibitory receptors on the surface of T-cells allows the immune system to attack tumour cells. Thus, antibodies against cytotoxic T-lymphocyte-associated protein 4 (CTLA-4), programmed cell-death protein 1 (PD1), and PD-ligand 1 (PD-L1) have passed through clinical trials and succeeded to become one of the mainstream

\begin{tabular}{|c|c|c|c|}
\hline Sr. No & Targeted therapy & Brand examples & Main mechanism of action \\
\hline 1 & Axitinib & Inlyta $^{\circledR}$ & Angiogenesis inhibition \\
\hline 2 & Bevacizumab & Avastin $^{\circledR}$, Mvasi $^{\text {TM }}$ & Angiogenesis inhibition \\
\hline 3 & Cabozantinib_ & Cabometyx $^{\text {TM }}$ & Angiogenesis inhibition \\
\hline 4 & Everolimus & Afinitor $^{\circledR}$ & m-TOR pathway inhibition \\
\hline 5 & Lenvatinib mesylate & Lenvima $^{\circledR}$ & Tyrosine kinase inhibitor \\
\hline 6 & Nivolumab & Opdivo $^{\circledR}$ & PD1-immune checkpoint inhibitor \\
\hline 7 & Pazopanib & Votrient $^{\circledR}$ & Angiogenesis inhibition \\
\hline 8 & Sorafenib & Nexavar $^{\circledR}$ & Angiogenesis inhibition \\
\hline 9 & Sunitinib & Sutent $^{\circledR}$ & Angiogenesis inhibition \\
\hline 10 & Temsirolimus & Torisel $^{\circledR}$ & m-TOR pathway inhibition \\
\hline
\end{tabular}

Table 1: FDA-approved targeted therapies in renal cell carcinomas.

*Corresponding author: Dr. Sadia Ajaz, Assistant Professor, Molecular Oncology (P-035) Lab, Dr. Panjwani Center for Molecular Medicine and Drug Research (PCMD), International Center for Chemical and Biological Sciences (ICCBS) University of Karachi, Karachi-75270, Pakistan, Tel: +922134824924-5 (Ext) 305; Fax: +922134819018-9; E-mail: sadiaajaz.pcmd@iccs.edu

Received October 28, 2018; Accepted November 10, 2018; Published November 14, 2018

Citation: Ajaz S, Abid A (2018) An Update on Targeted Therapies in Renal Cell Carcinomas. J Mol Genet Med 12: 377 doi:10.4172/1747-0862.1000377

Copyright: @2018 Ajaz S, et al. This is an open-access article distributed under the terms of the Creative Commons Attribution License, which permits unrestricted use, distribution, and reproduction in any medium, provided the original author and source are credited 
therapies in cancers [9]. Nivolumab is a PD1 immune checkpoint inhibitor, which has been approved for mRCC [10].

\section{Discussion and Conclusion}

With the advent of these targeted agents, overall survival for RCC has improved. Patients are being treated continuously for increasingly long periods of time. However, these treatments rarely yield complete responses and are not curative. Therefore, search for suitable target(s) and development of specific therapies in RCCs must persist.

\section{References}

1. Znaor A, Lortet-Tieulent J, Laversanne M, Jemal A, Bray F (2015) International variations and trends in renal cell carcinoma incidence and mortality. Euro Urology 67: 519-530.

2. Bukowski R, Figlin RA, Motzer R (2009) Renal cell carcinoma: Molecular targets and clinical applications. Springer Science and Business Media, United States.

3. https://www.cancer.gov/about-cancer/treatment/types/targeted-therapies/ targeted-therapies-fact-sheet.
4. Srinivasan R, Ricketts CJ, Sourbier C, Linehan WM (2015) New strategies in renal cell carcinoma: Targeting the genetic and metabolic basis of disease. Clin Cancer Res 21: 10-17

5. Hsieh JJ, Purdue MP, Signoretti S, Swanton C, Albiges L, et al. (2017) Renal cell carcinoma. Nature Rev Dis Primers 3: 1-2.

6. Badal AM, Aiken S, Chin N (2017) Molecular targets and angiogenesis in renal cell carcinoma, a multitarget approach: Mini review. Curr Drug Targets 18: 1204-1213.

7. Motzer RJ, Hutson TE, Glen H, Michaelson MD, Molina A, et al. (2015) Lenvatinib, everolimus and the combination in patients with metastatic renal cell carcinoma: A randomised, phase 2, open-label, multicentre trial. Lancet oncology 16: 1473-1482.

8. Mahalingam D, Medina EC, Esquivel JA, Espitia CM, Smith S, et al. (2010) Vorinostat enhances the activity of temsirolimus in renal cell carcinoma through suppression of survivin levels. Clin Cancer Res 16: 141-153.

9. Alberts B, Bray D, Lewis J, Raff M, Roberts K, et al. (2015) Molecular biology of the cell, Garland, $\left(6^{\text {th }}\right.$ edn. $)$, New York, USA.

10. Ochoa CE, Joseph RW (2018) Nivolumab in renal cell carcinoma: Current trends and future perspectives. J Kidney Cancer VHL 5: 15 